\title{
LA DOBLE MARGINALIDAD DEL MONSTRUO HUMANO MODERNO: EL CÍCLOPE POLIFEMO EN LOS PEOR, DE FERNANDO CONTRERAS CASTRO
}

\author{
Irene González, Muñoz
}

\section{(9) $(\Theta \Theta$}

Esta obra está bajo una licencia Creative Commons 



\title{
LA DOBLE MARGINALIDAD DEL MONSTRUO HUMANO MODERNO: EL CÍCLOPE POLIFEMO EN LOS PEOR, DE FERNANDO CONTRERAS CASTRO
}

\author{
DOUBLE MARGINALITY OF THE MODERN HUMAN MONSTER: \\ POLYPHENUS THE CYCLOPS IN LOS PEOR BY FERNANDO \\ CONTRERAS CASTRO
}

\author{
Irene González Muñoz
}

\begin{abstract}
RESUMEN
Según lo afirman Chevalier y Gheerbrant, en la cosmovisión clásica grecorromana, el cíclope se concibe como una fuerza primitiva o regresiva. En este sentido, su monstruosidad se fundamenta en lo anormal de su constitución física y de su comportamiento salvaje; sin embargo, se trata de seres propicios para los dioses, lo cual se justifica por su origen divino. En la novela Los Peor, de Fernando Contreras Castro, la cual se desarrolla en el submundo de la sociedad contemporánea, el cíclope Polifemo Peor deviene, tanto por su condición humana como por su anomalía física, en el monstruo humano moderno, tal como se desprende de las propuestas de Canguilhem. Además, su monstruosidad reside en la transgresión del límite natural, al darse en él la mixtura vida/muerte, según lo plantea Foucault. Así, como monstruo humano moderno sufre de una doble marginación. La primera, en el mundo mostrado de la novela por ser un marginado dentro de los marginados; la segunda, al ser conceptualmente atenuado como monstruo, gracias al logos de la modernidad. Palabras clave: Literatura costarricense, novela, el monstruo en la literatura, Contreras-Castro, Fernando.
\end{abstract}

\begin{abstract}
According to Chevalier and Gheerbrant in the Greco-Roman classical world view, the Cyclops is conceived as a primitive or regressive force. In this sense, his monstrosity is based on the abnormality of his physique and his wild behavior; however, it is related to beings that are suitable to the gods, which is justified by their divine origin. In the novel Los peor by Fernando Contreras Castro, which takes place in the underworld of contemporary society, the cyclops Polyphemus Peor becomes, not only because of his human condition, but his physical anomaly, the modern human monster as is derived from G. Canguilhem's proposals. Also, its monstrosity resides in the transgression of the natural limit, giving him the mixture of life and death, as proposed by $\mathrm{M}$. Foucault. Thus, as a modern human monster he suffers a double marginalization. The first one, as shown in the world of the novel by being marginalized within the marginalized and the second, being conceptually diminished as a monster, thanks to the logos of modernity.
\end{abstract}

Key words: Costa Rican literature, novel, the monster in literature, Contreras-Castro, Fernando.

\footnotetext{
M.L. Irene González Muñoz. Universidad de Costa Rica. Profesora de la Escuela de Filología, Lingüística y Literatura. Costa Rica. Correo electrónico: irenego123@hotmail.com
}

Recepción: 15- 04- 2015

Aceptación: 19- 06- 2015 
La representación de lo monstruoso siempre ha tenido cabida en las manifestaciones culturales del ser humano y, la literatura, en tanto producto cultural que nos ocupa en este coloquio, no escapa a este fenómeno, de hecho se trata del medio de expresión que a lo largo del desarrollo de la cultura le ha dado forma y, en muchas ocasiones, un cuerpo y un rostro específicos a los grandes miedos del ser humano. De esta manera, cada época y cada cultura han construido y representado a sus propios monstruos. Así, hemos conocido a los monstruos de la mitología clásica, por ejemplo las Gorgonas o el Minotauro, o a los monstruos del romanticismo; entre ellos, Drácula y Frankenstein. Precisamente, la literatura contemporánea no escapa a esa tendencia por novelar sobre el monstruo, tal es el caso particular del texto Los Peor, de Fernando Contreras Castro, en el cual se representa al monstruo humano en el personaje del niño Polifemo Peor, que sin duda alguna, se ha convertido en uno de los monstruos de la literatura costarricense.

\section{Los Peor y la crítica}

Antes de considerar las propuestas de lectura que ya se han llevado a cabo sobre Los Peor, es pertinente referir el resumen de la historia que se narra en esta novela, la cual gira, en principio, en torno a Jerónimo Peor, un ex monje que está loco, según se plantea en la misma novela, y que vuelve a la ciudad de San José después de muchos años de ausencia. Precisamente, a su regreso busca a su hermana, Consuelo Peor, quien trabaja y vive con su esposo lisiado en una pensión, cuyas huéspedes se dedican a la prostitución. Jerónimo es acogido por su hermana en este prostíbulo y, una vez ubicado en él, se dedica recorrer, de día y de noche, las calles de la ciudad. Una noche, una joven campesina, con unos seis meses de embarazo, se desmaya frente a la pensión y es rápidamente atendida por las muchachas de la casona. La dueña del local, Elvira Morales, manda a llamar al doctor Evans, médico de la pensión, para que examine a la joven. El médico dictamina que la muchacha presenta un cuadro severo de intoxicación. Jerónimo, quien había aprendido a curar con hierbas, en cuanto se entera del asunto, empieza a recetarle una serie de medicinas naturales que muy pronto restablecen la salud de la joven. Todas las mujeres de la pensión deciden que la muchacha, cuyo nombre es María, se quede mientras recupera su salud. Tiempo después, llega el momento del parto y María da a luz, en la pensión, a un niño cíclope. Al principio, tanto el médico como las mujeres del local y la propia madre del niño se horrorizan al ver al recién nacido, salvo Jerónimo, quien inmediatamente se hace cargo de él. Evans le indica que los niños con esa condición no sobreviven; sin embargo, el ex monje le responde que ese sí vivirá y decide llamarlo Polifemo. A partir del nacimiento del pequeño cíclope, la vida de Consuelo y la de Jerónimo, sobre todo, empiezan a girar en torno al niño, son ellos quienes deciden que para protegerlo, debe permanecer recluido en la pensión y es Jerónimo quien se encargará de educarlo. Así, a los cuatro años, Polifemo domina el latín, y según Jerónimo, ya está listo para aprender griego y las materias del Trivium y del Quadrivium. A pesar de que su confinamiento en la pensión tarda varios años, Polifemo tiene la oportunidad de salir a recorrer las calles, gracias a una gorra de beisbol que le regala su madre. En sus recorridos con Jerónimo por la ciudad, se relaciona con los niños de la calle, los mendigos, los taxistas nocturnos y todos los personajes marginales de la ciudad, quienes no lo consideran diferente. Finalmente, a la edad de ocho años empieza a sufrir de epilepsia por lo que es internado en el Hospital de Niños, donde al tiempo muere. Para evitarle penas, a Jerónimo le dicen que Polifemo se transformó 
en un vegetal y a los días le entregan un arbolito de limón, lo cual alegra al ex monje, pues el niño se convirtió en un Arbor Medica, y decide sembrarlo en la zona verde del Hospital de Niños. Tiempo después Jerónimo muere al pie del limonero.

En cuanto a la crítica sobre la obra de Contreras, Flora Ovares y Margarita Rojas (1995), inscriben la producción textual de este escritor dentro de la que ellas denominan la generación del desencanto; no obstante, afirman que en práctica escritural "se revela un grado mayor de confianza en la posibilidad comunicativa de la literatura, como un acto de transmisión de un saber y como denuncia de una situación indebida" (Ovares y Rojas, 1995, p. 244).

Por su parte, en "Miradas convergentes sobre la ciudad en Los Peor de Fernando Contreras", María Henríquez (2005) propone, en general, que en esta novela se realiza un recorrido por la realidad urbana a través de la mirada de tres de sus personajes: Jerónimo, Félix y Polifemo, pues es a partir de la percepción y de la interpretación que estos personajes realizan de la ciudad, que esta se nos presenta a los lectores como un espacio dual, ya que existe una San José de día y otra, de noche. Más aún, según esta autora, existe la ciudad que describe el ciego Félix a partir de sus recuerdos, la de antaño; existe, además, la que concibe o inventa Jerónimo y, por último, existe la que ve Polifemo, porque lo que el niño cíclope ve, desde su confinamiento en la pensión "a través de la valla pone en tela de juicio la correspondencia entre la enseñanza que ha recibido y la realidad. El niño, desde su "monócula visión”, aprende a mirar la calle y no vacila en refutar las explicaciones de su mentor" (Henríquez, 2005, p. 62). Así, a través del recorrido que realizan estos tres personajes por San José, conocemos, sobre todo, a los otros seres que la pueblan, aquellos con los que interactúan Jerónimo y Polifemo: los niños de la calle, los jóvenes delincuentes, los vendedores ambulantes, los travestis, los mendigos, etc., en suma, los marginados.

Para Henríquez, Los Peor muestra los dos polos de la realidad urbana: "la Calle (en su sentido arquetipal) y la diferencia, dos polos de la realidad urbana [...] recreada en diferentes grados por la ficción" (2005, p. 64), lo que permite la construcción de la ciudad a partir del recuerdo y de la mirada de los personajes.

Concretamente, sobre Polifemo, lo concibe como un personaje alegórico que representa "el signo de nuestros tiempos" (como lo afirma Jerónimo en la novela), y concluye que su transformación en árbol que se planta en el jardín del Hospital de Niños es el signo de una posible reconciliación entre el hombre, la naturaleza y el mundo urbano (Henríquez, 2005).

Carlos González Hernández (2014), en su estudio "Espacios predominantes en la novela Los Peor de Fernando Contreras Castro", clasifica el texto como novela urbana o de ciudad. Realiza un amplio análisis del espacio en ella, y a partir del epígrafe de San Agustín, que Contreras toma del libro La ciudad de Dios, asegura que esta novela ofrece una crítica "a los conglomerados humanos, que en múltiples ocasiones, no toleran a los seres que se salen de las normas establecidas; donde muchas veces lo monstruoso adopta y protege a los más desvalidos habitantes de las urbes josefinas" (sic) (González-Hernández, 2014, p. 6).

Otro artículo considerado en esta revisión bibliográfica es el de Óscar Alvarado (2006), "La incidencia de lo posmoderno en la novela Los Peor, de Fernando Contreras". El planteamiento central de Alvarado consiste en que esta novela es producto de la influencia de la posmodernidad, ya que en ella se da la ruptura con la visión idílica y progresista del espacio urbano moderno y, por el contrario, presenta una relectura del espacio que conlleva a la emergencia de nueva literatura, que toma como base la ciudad con todas sus manifestaciones 'oscuras' y 'desdichadas'. 
Siguiendo esta línea, plantea que en la novela la marginalidad es un tema importante, pues evidencia que esta 'ataca' a unos sujetos más que a otros; por esto, la presencia del niño cíclope en la historia narrada no es casual. Polifemo se convierte, así, en el símbolo de un nuevo orden, de un nuevo sistema de valores, que de acuerdo con Alvarado, reafirman la diferencia y la marginación de los sujetos y de los grupos (Alvarado, 2006); en otras palabras, para Óscar Alvarado, Polifemo debe considerarse como el marginado dentro de los marginados.

Finalmente, en "Si algo pudiera llevarme a la muerte eso sería el ruido del mar, lectura de Los Peor como estética de los excluidos", Jorge Jiménez (1998) plantea que en Los Peor el mundo mostrado es el de los excluidos, la historia de sus personajes es la de la sus vidas cotidianas en un espacio urbano decadente y atrofiado, producto de una modernización 'galopante', en el que se ha producido todo un 'bestiario barroco', pues:

Los personajes de «Los Peor» como habitantes del «lado oscuro», han logrado trasvasar los límites de la realidad cotidiana por una condición que los asimila a lo monstruoso y a lo grotesco. [...] Pero en esa asimilación a lo monstruoso, los personajes de novela alcanzan a construir un mundo simbólico que transforma su indigencia externa en una existencia enriquecida por la profundidad de unas relaciones humanas signadas por la entrega y la pasión (Jiménez, 1998, p. 42)

Nótese que a pesar de la concepción monstruosa de los personajes de Los Peor, Jiménez plantea a la vez su condición humana signada por los mejores valores, entre ellos, por ejemplo, el amor y la ternura.

Así, el abordaje crítico a esta novela revela la importancia del espacio urbanomarginal, el cual se representa como caótico y peligroso; sin embargo, los personajes de la historia deambulan por él sin mayores complicaciones, lo cual se explica debido a que estos son, en su totalidad, seres marginados.

En síntesis, la crítica revisada plantea tres aspectos por considerar en esta propuesta. El primero de ellos, la concepción de la literatura como instrumento para canalizar un saber a través de la denuncia. En segundo lugar, se colige que esta denuncia consiste en evidenciar los males que el progreso, gran promesa de la modernidad, ha generado en los grandes espacios urbanos y en los seres que los habitan, lo que nos lleva al tercer aspecto por considerar y que respecta al rol de Polifemo dentro de la historia narrada. En este sentido, la crítica considera al niño cíclope, por una parte, como un personaje alegórico, en tanto que su constitución morfológica es la representación de la mala relación ser humano/naturaleza y, por otra parte, por su condición de ser diferente, se le considera no solo el marginado por excelencia, sino también como el símbolo que en el mundo mostrado reafirma los valores (como el amor, la ternura y la solidaridad) de la diferencia; es decir, de los excluidos.

\section{Sobre la conceptualización del monstruo humano}

La acepción más común de monstruo es la que se registra en el Diccionario de la Real Academia Española, la cual reza que monstruo es cualquier producción que vaya contra el orden regular de la naturaleza, ya sea que se trate de un ser fantástico que causa espanto, de algo que es excesivamente grande o extraordinario en cualquier aspecto, como también lo puede ser una persona o una cosa muy fea, o una persona muy cruel y perversa.

Ante este panorama, nadie más incomprendido ni más aislado, en un principio, que un monstruo, por su condición de raro, extraño, inclasificable o extraordinario. Aparte de ser considerado como verdadera amenaza, tanto para la seguridad personal como para la 
comunitaria, y como agente de la inminente pérdida del orden y del control que se ambiciona para sustentar el orden establecido y su transmisión a una próxima generación.

Georges Canguilhem (2001), en "La monstruosidad y lo monstruoso", asevera que monstruo es una categoría aplicable a los seres orgánicos (no hay monstruos ni mecánicos ni minerales). Afirma también que este, debido a su diferencia morfológica, nos lleva a cuestionar el poder de la vida para mostrar el orden. Más aun, el temor de lo que Canguilhem denomina un malogro morfológico, un monstruo, lleva al ser humano a considerarlo no solo como un fracaso del orden regular de la naturaleza, sino que a la vez, lo puede llevar a pensar en la posibilidad de que ese malogro haya sido causado por la propia acción del ser humano. De esta manera, plantea que el monstruo se considera, entonces, como un ser viviente con un valor negativo.

Para este médico y filósofo francés, el monstruo es lo otro, "un orden distinto al orden más probable" (Canguihem, 1962, p. 33) y, siguiendo al psicólogo social Gabriel Tarde, afirma, que el "tipo normal es el cero de monstruosidad" (Canguihem, 1962, p. 35). En palabras de Marcos García de la Huerta, quien fundamenta su propuesta en la anterior afirmación, el definir la normalidad de esta forma, es sugerente porque:

\section{en lugar de ver lo monstruoso desde la normalidad y consiguientemente de repelerlo como contranatura, permite entenderlo como un caso límite de una continuidad vital. Se establece así un principio para despojar a los monstruos de esa aura de repulsión y fascinación, de horror y deslumbramiento con que suele rodearlos el sentido común... (García de la Huerta, 2001, párr. 16)}

Es decir, que este recurso discursivo positivista, no solo despoja al monstruo del aura demoníaca y repulsiva que se le adjudicó durante la Edad Media, sino que además, trae lo monstruoso a la norma al ubicarlo en un continuum biológico, con el afán de explicar el nacimiento del monstruo como un producto de la descompensación en ese continuum.

De acuerdo con Canguilhem (lo mismo plantea Foucault), esta necesidad del pensamiento positivista de construir un conocimiento científico que diera cuenta de las causas, de la existencia y de la clasificación del monstruo, provocó que este no solo fuera objeto de la ciencia, sino también su instrumento y, con esto, sufrió un proceso de desmitificación.

En relación con lo anteriormente expuesto, Michel Foucault (2001) plantea, en Los Anormales, que en el siglo XIX, se empieza a estudiar y a abordar el ámbito de la anomalía a partir de tres figuras: el monstruo humano, el individuo a corregir y el niño masturbador; es decir, que en estas tres figuras se sustenta no solo el discurso sobre la problemática de la anomalía humana, sino también las técnicas judiciales y médicas de los siglos XIX y XX para tratar, precisamente, estas anomalías. Para efectos meramente operacionales de la presente ponencia, centraré mi interés en la noción del monstruo humano que describe este autor, ya que es esta la figura que nos ocupa en el caso de la novela Los Peor, de Fernando Contreras Castro.

De acuerdo con Foucault, el monstruo humano es esencialmente, en un sentido amplio, una noción jurídico-biológica. Lo plantea de esta forma, pues afirma que lo que define al monstruo es que tanto su existencia como su forma violan no solo las leyes de la sociedad, sino también las de la naturaleza; por esto, establece que el monstruo es lo que combina lo prohibido y lo imposible. Así, el monstruo humano es "el límite, el punto de derrumbe de la ley y, al mismo tiempo, la excepción que sólo se encuentra, precisamente, en casos extremos" (Foucault, 2001, pp. 57-58). A partir de lo anteriormente expuesto, afirma, en primera instancia, que el monstruo humano, morfológicamente hablando, contradice la ley, pero esta infracción no genera una respuesta legal, a lo sumo, lo que podría provocar es la discusión acerca de los cuidados que este demande o la violencia que se ejerza contra él o, 
incluso, su supresión/exclusión de la sociedad. En segunda instancia, el monstruo representa la forma natural de la contranaturaleza, es la anomalía y, en cuanto ser anómalo o anormal, es por definición, la excepción:

\begin{abstract}
el monstruo es, en cierto modo, la forma espontánea, la forma brutal, pero, por consiguiente, la forma natural de la contranaturaleza. Es el modelo en aumento, la forma desplegada por los juegos de la naturaleza misma en todas las pequeñas irregularidades posibles. Y en ese sentido, podemos decir que el monstruo es el gran modelo de todas las pequeñas diferencias. Es el principio de inteligibilidad de todas las formas [...] de la anomalía (Foucault, 2001, p. 58)
\end{abstract}

Otras características importantes del monstruo humano son, en primer lugar, que su índice de frecuencia es muy bajo; es decir, se trata de una excepción, como ya hemos dicho, se trata de lo extraordinario; y en segundo lugar, su monstruosidad es diáfana, se muestra. Debido a esto, según lo expresa Foucault, el saber sobre el monstruo humano es el que más se va a desarrollar a fines del siglo XVIII y principios del XIX, esto con la finalidad de establecer y sustentar la práctica científico-jurídica en torno a esta figura, en términos de qué hacer con los seres monstruosos, pues como modelo de la anomalía, como fenómeno contingente dentro del sistema social, requiere de un discurso que norme su existencia dentro del orden jurídico: "El monstruo es [...] la casuística necesaria que el desorden de la naturaleza exige en el derecho" (Foucault, 2001, p. 65).

Precisamente, el campo del saber en el que se ubica la figura del monstruo humano es el de la historia natural, que considera la distinción absoluta e infranqueable de las especies, los géneros y los reinos. Así, retomando ideas que se generan en la Edad Media, en los siglos XVIII y XIX, se va a concebir al monstruo humano como el producto de la mezcla entre dos especies (dos animales diferentes), de dos individuos (el caso de los llamados siameses), de dos sexos (los hermafroditas), o de la mezcla de vida/muerte (en el caso de los niños que nacen con una morfología que no les permite vivir); o sea, de una mixtura de formas, de una transgresión del límite de lo natural; es decir, para que haya monstruosidad:

\footnotetext{
es preciso que esa transgresión del límite natural, esa transgresión de la ley marco sea tal que se refiera a, o en todo caso ponga en entredicho, cierta prohibición de la ley civil, religiosa o divina, o que provoque cierta imposibilidad de aplicar esa ley civil, religiosa o divina. Sólo hay monstruosidad donde el desorden de la ley natural toca, trastorna, inquieta el derecho, ya sea el derecho civil, el canónigo o el religioso (Foucault, 2001, pp. 64-65)
}

Así, a partir de esta necesidad de explicar o de entender la existencia del monstruo humano, del anormal, se generó todo un discurso que lo define, lo describe y lo clasifica, y esto conlleva a que desde finales del siglo XIX y principios del XX, se le conciba como un monstruo cotidiano, como un monstruo trivializado, pálido (Foucault, 2001).

\title{
3. La doble marginalidad de Polifemo
}

En el Diccionario de símbolos de Chevalier y Gheerbrant (1988), se establece que en la tradición griega el cíclope es una fuerza primitiva o regresiva, cuya monstruosidad se fundamenta en lo anormal de su constitución con respecto a los humanos, debido a su gran estatura, al hecho de poseer un solo ojo y a lo salvaje de su comportamiento; sin embargo, se trata de una figura propicia a los dioses. Pierre Grimal (1979) afirma que en la antigüedad clásica se distinguían tres especies de cíclopes, que como seres mitológicos y de origen divino, se ajustaban al orden de la cosmovisión de la época, pues a pesar de su particular fisonomía respondían a los designios de los dioses. Además, se debe notar que en este orden del cosmos, no se trata de seres humanos. 
En el caso específico de Polifemo Peor, el niño cíclope, es preciso establecer y caracterizar, en primera instancia, el espacio en el cual se da su nacimiento, para luego referir su condición en él.

Como ya hemos dicho, su madre se desmaya por azares del destino justo frente a la puerta principal de la pensión-prostíbulo, ubicada en una zona marginal de la ciudad, cerca del mercado central. María, pues ese es su nombre, es acogida en esta casona, por las muchachas y la dueña para que se restablezca del cuadro de intoxicación que padece. En esta misma casa viven los hermanos Consuelo y Jerónimo Peor. Lo interesante de esta pensión consiste en que todos sus habitantes muestran una rareza; así, la dueña de la casa dice de sí misma que ella debe "ser la única puta virgen del mundo" (Contreras, 1995, p. 225). Consuelo, la hermana de Jerónimo, exhibe unos descomunales 'brazos de amazona' capaces de asfixiar a cualquiera, como lo hace con un cliente del prostíbulo que puso en duda la cordura de su hermano. El hombre de Consuelo, como lo llama la voz narrativa, es más grande que ella y está como muerto en vida desde el día en que sufrió una descarga eléctrica en un accidente laboral. Jerónimo, el ex monje, viste siempre un hábito de la orden franciscana, se dedica a deambular por la ciudad y tiene, entre otras, la costumbre de chupar las aceras, las paredes de los edificios y las calles de la ciudad, sobre esto nos dice la voz narrativa que:

Con esa majadería había aprendido ya que la "hermana ciudad", cómo él le decía, no sabía igual en todas partes, que bastaba con lamer delicadamente la acera del Correo para darse cuenta de que había en ella un fuerte sabor a frutillas de los árboles y a excremento de perro (Contreras, 1995, p. 28)

En fin, se trata de una pensión habitada por personajes extraños.

Como se puede constatar, los habitantes de la pensión-prostíbulo distan mucho de ser los más normales y es en este particular ambiente en el que nace Polifemo, un día de noviembre al caer la tarde.

Precisamente, el día en que nace el niño el doctor Evans fue mandado a llamar para que atendiera el parto, el cual tardó mucho y fue muy difícil, incluso una muchacha gorda se sentó encima de María para que la labor fuera más rápida. Finalmente, nació el niño con buen color, buen peso y buen tamaño; sin embargo, una vez que lo vieron, el asombro embargó a todos los presentes, incluso a su madre, quien lo rechazó al constatar que en la frente del niño había un solo ojo:

\footnotetext{
El niño era diferente. Se lo enseñaron a la madre que lo pedía a gritos porque el llanto de todas las muchachas la hacía sospechar la desgracia; se lo dieron y lo soltó en medio de un alarido. [...] El niño, en todo era perfectamente normal excepto porque en su frente había un único ojo grande, negro y hermoso (Contreras, 1995, pp. 34-35)
}

Con el nacimiento de este niño cíclope, se origina toda una discusión entre los miembros de la pensión y el médico, el objetivo de esta es decidir qué hacer con el pequeño. Evans les advierte que los niños cíclope nunca sobreviven al parto y que cuando lo hacen, como en el caso de Polifemo, no viven mucho tiempo. Ante este panorama, deciden que el bebé se quede en la pensión, pero fuera de la vista de todos aquellos que visitan el prostíbulo, pues sobre todo doña Elvira teme, entre otras cosas, verse envuelta en problemas legales por la permanencia de un ser tan raro en su pensión; además, según lo confirma la voz narrativa, la decisión de ocultarlo se toma "por razones obvias, primero por raro, segundo porque no sería bautizado y tercero porque si algún malintencionado de afuera llegara a descubrirlo, seguramente avisaría al Patronato Nacional de la Infancia o querría vendérselo a un circo" (Contreras, 1995, p. 36). 
A partir de la cita anterior quedan más que establecidas las características del monstruo humano, en su dimensión jurídico-biológica y religiosa. En primera instancia, Polifemo es un niño raro debido a su anomalía morfológica, que además es tan obvia, que lo pone en riesgo no solo de ser legalmente ‘confiscado’ por una institución estatal, sino que también corre el peligro de ser objeto del comercio ilegal. Ahora bien, su rareza no se limita únicamente a lo evidente, ya que es mucho más extraordinario y contranatural que siendo un niño cíclope en el que la mixtura vida/muerte está patente, este sobreviva. Otro dato importante que se extrae de esta cita es el hecho de que no será bautizado, y como nos damos cuenta más adelante en la historia, tampoco será inscrito en el Registro Civil, esto con la idea de que no haya rastro de su existencia. Con estas medidas, se confirma que Polifemo es la mostración de lo otro, de lo que se separa del orden y, por esta razón, y para protegerlo, es excluido de la sociedad, de manera que su mundo se restringirá, en lo sucesivo, a un cuartito instalado en el patio de la casona, fuera de la vista del resto del mundo, pues es la constatación del modelo de la diferencia. Su madre, incluso duda de su humanidad al asegurar que “...lo que ese niño tiene es que no es humano... Él es sólo un castigo que el cielo me mandó por abrir las piernas tan fácilmente...” (Contreras, 1995, p. 39).

Es evidente, entonces, que a pesar de que todos los habitantes de la pensión son personajes raros también, asumen a Polifemo como un ser extraordinario y excepcional en comparación con ellos y, por lo tanto, se constituye en el otro dentro del orden (de rareza) de la casona. Su propia madre lo rechaza: "Ella no quería al niño y ahora tampoco quería a nadie; no lo quería por raro [...] Le tenía miedo, sentía por él la repulsión que cualquiera siente ante lo que aprendió a distinguir como extraño, ajeno y amenazante" (Contreras, 1995, p. 39). En otras palabras, Polifemo es marginado en un mundo de marginados.

Como vemos, a pesar de que María no logra querer a Polifemo como su hijo, sí asume la responsabilidad por su malformación, pues está convencida de que se debe a un castigo divino por haber tenido relaciones sexuales fuera del matrimonio. Para el doctor Evans la causa es otra:

\footnotetext{
Él se lo atribuía todo al origen de la madre: campesina de las zonas agrícolas de Alajuela, había vivido su vida y embarazo expuesta al contacto con los agroquímicos todo el tiempo que logró disimularlo, hasta ser descubierta y expulsada de la casa. No era la primera vez que algo así sucedía en el país, aunque sí la primerísima que un niño de estos lograba sobrevivir (Contreras, 1995, p. 37)
}

Luego nos enteramos de que cuando el padre de María descubrió que estaba embarazada, la castigó físicamente y la subió al camión junto con la carga de productos agrícolas que llevaba a vender al mercado en la ciudad, donde después la abandonó.

Como se constata, tanto María como Evans parten de la idea de que la anomalía del niño fue causada por la acción humana; en el caso de la madre, debido a su pecado, pero el médico la atribuye a un hecho externo, en este caso a la acción humana contra la naturaleza, por la utilización de productos agroquímicos.

Ante el rechazo del niño por parte de María, Jerónimo y Consuelo se hacen cargo de su cuidado, tanto en lo que respecta a su alimentación como a su educación. Así, desde sus primeros balbuceos, Jerónimo se dio a la tarea, como lo expresa la voz narrativa, de enseñarle el costarricense y el latín de forma simultánea, y con estas enseñanzas lo que consiguió fue agravar más aún la rareza del niño en relación con resto de los huéspedes de la casona, tal como lo expresa su madre: "Tras que no es raro el pobre, encima le enseñan a hablar como si fuera un cura de los de antes!..." (Contreras, 1995, p. 76). No contento con haberle enseñado latín, Jerónimo le enseña a contar, a recitar y a narrar historias de la mitología clásica. También le enseña cantos gregorianos que el niño ejecuta con una afinada voz de soprano. Cuando cumple cuatro años, 
el ex monje decide que además de latín, debe aprender griego, Historia Natural, Gramática y Retórica, así como Música, Matemáticas, Medicina y Astronomía. Este modelo de educación totalmente anacrónico contribuye, por una parte, a acrecentar la rareza del niño cíclope y, por otra, a evidenciar su capacidad intelectual para aprender, lo cual demuestra que, contrario a lo que temía el viejo doctor Evans, Polifemo no presenta problemas cerebrales. Esto hace que el hijo de Evans, quien es médico pediatra, lo considere un prodigio de la naturaleza después de auscultarlo:

\footnotetext{
Alberto Evans pudo auscultar al cíclope para asombrarse aún más de que todo estuviera en su lugar y funcionando perfectamente, hasta el ojo único en medio de la frente. Su asombro tocó fondo cuando lo escuchó comunicarse en latín con Jerónimo: no sólo no había el menor problema en él, sino que además era especialmente inteligente (Contreras, 1995, p. 101)
}

Así, la vida del niño cíclope transcurre tranquilamente dentro de las paredes de la casona; sin embargo, esto cambia después de que su madre le regala una gorra de beisbol que le tapa la frente de tal manera que su ojo no es visible para los demás, pero él sí puede ver a través de la redecilla. Cuando Jerónimo se entera de esto y después de constatar con las muchachas que con la gorra no se le nota el ojo, decide sacar al niño de la pensión y llevarlo a conocer la ciudad. De esta forma se termina el periodo de reclusión física de Polifemo; no obstante, en adelante se ocultará bajo la gorra de beisbol, lo cual le permitirá conocer no solo la ciudad, sino también a una serie de personajes que transformarán su vida: los vendedores del mercado, las meseras de las sodas, los travestis y a los niños cantores, entre otros. Una vez que Polifemo empieza a relacionarse con estos personajes, Consuelo se preocupa al notar la transformación del niño, pues empieza a actuar, según ella misma lo dice, como "un pachuquillo de la calle". Por ejemplo, cuando se da cuenta de que los niños cantores reciben dinero por cantar rancheras en los autobuses, él decide probar su suerte, pues considera que se trata de mero entretenimiento y no de un signo de mendicidad, por lo que convence a Jerónimo de que lo deje cantar en un autobús, a lo cual este accede:

\footnotetext{
Disculpen la molestia, damas y caballeros, yo vengo a cantarles una canción para que ustedes me ayuden con unas monedas, son para mi abuelito que está loco...- Jerónimo hizo una cara de asombro que causó risa en los primeros asientos. El niño cantó una cantiga de Alfonso X el Sabio con su hermosa voz de soprano y sorprendió tanto a los pasajeros que logró bastantes monedas. Cuando se bajaron del bus, el otro [otro niño] lo reprendió fuertemente:

-Mae, no cante así que van a creer que usté es un maricón- (Contreras, 1995, p. 176)
}

Después de esta experiencia, Polifemo aprende a cantar rancheras mejicanas, según nos lo aclara la voz narrativa, con "una más práctica impostación de la voz capaz de competir contra el bajo profundo y carrasposo del motor del bus" (Contreras, 1995, p. 177). Estos cambios en el comportamiento de Polifemo molestan a Jerónimo y causan recelo en Consuelo porque ven como del niño 'inocente' y 'prisionero', se va convirtiendo en uno más desenvuelto y menos ingenuo, deja de hablar latín y adopta el habla de los trameros. En una ocasión en que está hablando con Consuelo le dice: “-Mae, Consuelita, ¿vos sabés que mis amigos dicen que yo soy un dichoso...? - [Consuelo le pregunta] -Y eso ¿por qué? - [a lo que él responde] -Porque vivo en un putero..." (Contreras, 1995, p. 184).

De esta manera, después de la adquisición de la gorra que le permite esconder su anomalía en el exterior, los cambios que muestra Polifemo lo hacen más extraño aún ante los ojos de sus cuidadores. El mismo pediatra, Alberto Evans, le dice a Consuelo y a doña Elvira que el niño está irreconocible, tanto que si la gente se acostumbrara a verlo con su problema estético, pasaría por un ser normal, a lo que Consuelo responde: 


\begin{abstract}
-Pero imagíneselo en una escuela, con niños diferentes... bueno, diferentes son los niños con los que anda, más bien, imagíneselo con los niños comunes y corrientes de las escuelas, ¿usted cree que pueda aguantarse que le estén tomando fotos los periódicos y sacándolo en los reportajes sensacionalistas que tanto le gustan a la gente? - (Contreras, 1995, p. 199)
\end{abstract}

Como vemos, la preocupación por el bienestar de Polifemo es mayor una vez que este sale al mundo, a la calle, pues en la pensión están conscientes de que a pesar de la aceptación que ha tenido en la calle, esto se debe en primer lugar al hecho de que se codea con seres que también muestran alguna que otra 'anomalía' o 'rareza', como bien lo expresa Consuelo: “...bueno, diferentes son los niños con los que anda”. De hecho, estos niños llegan a aceptar de forma natural la singularidad de Polifemo, al punto de que cuando el niño se quitaba la gorra frente a ellos "su ojo solitario ya no causaba sorpresa aunque no dejara por ello de provocar cierta admiración: algunos de los chicos le confesaban al abuelo [Jerónimo] su deseo de ser cíclopes" (Contreras, 1995, p. 193).

Más adelante, y sobre el mismo tema, el doctor Evans le dice a María, a doña Elvira y a Consuelo que de no haber sido por ellas y su decisión de mantener a Polifemo en la pensión, su destino habría sido la reclusión en alguna institución hospitalaria, "porque si de algo se cuida la sociedad es de las cosas y las personas diferentes" (Contreras, 1995, p. 216). Para el médico es un error que haya salido de su reclusión, pues al imitar el comportamiento de los otros con los que se relaciona, su diferencia se le hará más pesada. Ante esto Consuelo le responde: “-Eso es porque nadie lo quiere aceptar así como él es-, [...] -y en eso sí que nadie le gana a Jerónimo, solo él lo ha querido sin reservas...” (Contreras, 1995, p. 217). Después de estas palabras de Consuelo, es más que claro que nadie, excepto Jerónimo, ha aceptado a Polifemo tal y como él es.

Jerónimo es el único que lo ha visto desde su diferencia y no frente a ella, más aun, es el único que realmente entiende su diferencia, tal y como se colige de la siguiente cita en la que el ex-monje acude a las palabras de San Isidoro de Sevilla para explicar al niño el origen de su morfología:

\footnotetext{
-Has de saber Polifemo, que entre portento y portentoso existe la diferencia de que los portentos son los que se transfiguran totalmente; así, se dice que en Macedonia, una mujer dio a luz una serpiente. Portentoso se dice solo de lo que sufre una leve mutación; mas no se crea que haya errado Dios en la creación de estos seres, porque ella es creadora de todas las cosas y sabe cuándo y dónde conviene o convino criar algún ser... (Contreras, 1995, p. 132)
}

En otras palabras, y como lo dice Jerónimo en repetidas ocasiones, Polifemo es "un signo de los tiempos", si nació con una anomalía, su existencia tiene un propósito, tal como lo asegura el propio Jerónimo, porque Dios así lo dispuso (nótese, por demás, que para este ex-monje Dios es una entidad femenina). Sin embargo, para Alberto Evans Polifemo no es un cíclope de aquellos con los que Jerónimo lo emparenta, pues en una ocasión en que el médico ausculta al niño este le refiere la historia (que Jerónimo le ha contado para justificar su apariencia física) sobre su tío cíclope, llamado también Polifemo, que fue pastor en Sicilia y que devoró a un tal Odiseo porque este último era un perverso. Por el contrario, para Evans la visible malformación del niño es el producto de la acción negativa del ser humano sobre la naturaleza, debido a los agroquímicos a los que su madre estuvo expuesta y, por esta razón, si la gente se acostumbra a la anomalía de Polifemo, entonces se correría el riesgo de que el problema de base, esa mala relación ser humano/naturaleza, pierda importancia y se olvide o, peor aún, que la anomalía se convierta en lo normal, como se lo dice a Consuelo: 
Pero imagínese usted, si la gente ve al niño en la calle y rapidito se acostumbra, menos se va a tomar el tiempo para pensar en que nos están envenenando a todos, a todos, con esas porquerías. Ahorita vamos a tener por las calles a los personajes esos de los que habla Jerónimo y va a ser muy fácil adivinar de qué parte del país es la gente, vea, nada más ve uno lo que tiene raro y con eso averigua si viene de Alajuela, de la zona Atlántica o de Guanacaste, eso va a depender de lo que se cultive en cada lugar y del producto químico que se utilice... (Contreras, 1995, pp. 211-212)

De estas palabras del médico se desprende que lo mejor sería que el niño siempre cause algún tipo de extrañeza en los demás, incluso entre los seres extra-ordinarios de la marginalidad, ya que de esta forma, su vida como monstruo tendría un propósito; a saber, anunciar, manifestar, mostrar y predecir las consecuencias negativas de una sociedad moderna que ha apostado por el progreso y sus prácticas científico-tecnológicas a costa del nacimiento de seres anómalos. De esta manera, en efecto, el niño cumpliría su misión, tal como lo asegura Jerónimo a María (citando a San Isidoro de Sevilla): “-El niño es un portento, un prodigio y un monstruo [...] El portento, pues, no es contranaturaleza, sino contra la naturaleza conocida" (Contreras, 1995, p. 46).

No obstante, es necesario centrarnos en esa misión que tanto Jerónimo como el médico le atribuyen a Polifemo, pues si el cometido de su existencia, según lo expresa Evans, es evidenciar que el uso de agroquímicos está generando nacimientos de seres humanos anormales, como es su caso, esta advertencia en el ámbito marginado en el que este niño se desenvuelve, no parece tener importancia alguna, pues a pesar de que el propio Jerónimo constantemente asegura que Polifemo es un signo de los tiempos, no cae en cuenta de cuál es la razón puntual por la cual el niño es un cíclope. Recordemos, además, que para la madre la anomalía del pequeño se debe a las relaciones sexuales ilícitas en las que fue concebido, mientras que para el resto de los personajes de la historia se trata de un niño con una deformidad física que muy pronto es aceptada, trivializada por la costumbre. De hecho, sus salidas a la ciudad con Jerónimo son posibles, gracias a que la gorra que María le regala, esconde su anomalía al punto de hacerla pasar desapercibida para los demás: "Jerónimo advirtió que Polifemo, con la gorra puesta [...], no difería en absoluto de los demás niños del mundo; sólo se veía como uno de ellos con una gorra más grande de la cuenta" (Contreras, 1995, p. 153). Incluso se advierte que el uso de esta gorra le permite llevar "encerrada su diferencia, más para proteger al mundo de ella que para protegerse él mismo del mundo" (Contreras, 1995, p. 156). Precisamente, proteger al mundo de su diferencia implica negarle su condición de monstruo, pues en efecto, pasa desapercibido como tal, ya que de hecho no exhibe una morfología que genere espanto entre los otros, ni el comportamiento perverso y cruel que suele atribuirse a los seres monstruosos.

En otras palabras, la verdadera tragedia de Polifemo no es ser marginado dentro de la marginalidad en la que se desenvuelve, la verdadera tragedia de este cíclope reside en que su anomalía se trivialice al punto de ser "invisibilizada", pues de esta forma su condición de monstruo humano se ve disminuida. Esto se evidencia no solo en el hecho de que todos los personajes extra-ordinarios de la historia se acostumbran con naturalidad a la anomalía del niño, sino también en el hecho de que el único que atribuye la malformación de Polifemo al efecto de los productos agroquímicos a los que estuvo expuesta María es el doctor Evans hijo, quien precisamente, una vez ingresado el niño en el hospital, solicita a los médicos no hacer pública la existencia del pequeño ni su condición, por lo que el niño cíclope no transciende el espacio marginal. De manera que, como monstruo humano, Polifemo no consiga, al menos en el mundo mostrado de la novela, generar ni espanto ni temor entre los demás personajes, a pesar de ser el temido producto de la mala relación ser humano/naturaleza. 
Como vemos, el pequeño cíclope carece por completo de la capacidad sine qua non de todo monstruo de provocar espanto u horror entre quienes lo miran, baste con mencionar al licántropo, al tradicional vampiro o a los seres sobrenaturales de las leyendas populares, como La Llorona o el Cadejos, cuya condición monstruosa está signada por una maldición o la intervención demoniaca, razones de peso para ser considerados como seres temibles, mientras que la monstruosidad de Polifemo cuenta con una causa científica y racionalmente comprobable: los agroquímicos generaron su anomalía. Como vemos, este niño cíclope es, en efecto, "un signo de los tiempos" pues deviene en el paradigma del monstruo humano moderno, ya que es producto y víctima del desarrollo científico-tecnológico de la sociedad moderna. Se trata, entonces, de un monstruo posible o, hasta cierto punto, esperado, debido a que es consecuencia de la intervención humana en el medio. Así, según el orden de la modernidad, disciplinas como la medicina y la teratogénesis se han abocado a dilucidar el origen de los seres anormales y, con esto, siguiendo las propuestas de Canguilhem y García de la Huerta, se despoja al monstruo humano del aura de repulsión y de horror que tradicionalmente se le adjudicó.

De acuerdo con Foucault (2001), este recurso discursivo positivista que explica las causas, la existencia y la clasificación de lo monstruoso, ha generado todo un proceso para su desmitificación, lo que nos permite afirmar que Polifemo Peor es un claro ejemplo de ese modelo de la anomalía que, como fenómeno contingente dentro del sistema social, requiere de un discurso que norme su existencia y, de esta necesidad de explicar precisamente su existencia, que se le considere como un monstruo cotidiano, como un monstruo trivializado y pálido (Foucault, 2001).

De tal suerte, que en efecto, Polifemo es un ser marginado dentro de la marginalidad en que se mueve en la historia narrada, como lo ha planteado la crítica y lo hemos podido comprobar. No obstante, la mayor marginación de la que es víctima se da al ser conceptualmente disminuido como monstruo gracias al logos de la modernidad, lo cual nos lleva indefectiblemente a recordar y reconsiderar el epígrafe del grabado número 43 de la serie Los Caprichos (1799), de Francisco de Goya: "El sueño de la razón produce monstruos".

\section{Notas}

1. Desde la Edad Media, el monstruo, se relaciona con lo delictuoso, pues, en primera instancia, se considera como el producto de una infracción de orden sexual al irrespetarse la ley de la endogamia en aquellas uniones que no respetan la semejanza o, en su defecto, el producto de la imaginación, pues se parte de que la "imaginación no es aquí más que una función física imitativa, según la cual los objetos percibidos por una madre tienen un "contragolpe" sobre el niño en gestación" (Canguilhem, 1962, p. 38). De esta segunda causa, se entienden, por ejemplo, todas las ideas concebidas popularmente que los llamados "antojos" o las impresiones fuertes pueden causar en las mujeres embarazadas.

2. La primera generación, cuyo origen es divino (son hijos de Urano y de Gea), estaba compuesta por Brontes, Estéropes y Arges, quienes son hábiles en los trabajos manuales y proveen a Zeus con el rayo, a Hades con un casco que lo hacía invisible y a Poseidón con el tridente. Precisamente con estas armas los dioses del Olimpo vencen a los Titanes.

La segunda generación, a la cual pertenece el personaje de La Odisea, Polifemo, es la de los cíclopes sicilianos, que son considerados seres salvajes y gigantescos. Viven en cavernas, se dedican a la cría de carneros y son antropófagos. Polifemo es hijo de Poseidón y la ninfa Toosa, por lo que su origen también es divino y es caracterizado en La Odisea como el más salvaje y horrible de todos los cíclopes; además, de estúpido, razón por la cual a Ulises se le hace fácil engañarlo, cegarlo y huir así de su cueva.

La tercera generación es la de los cíclopes constructores, a quienes se les atribuye la construcción de los monumentos prehistóricos en Grecia y Sicilia. En este caso se trata de un pueblo que fue puesto al servicio de los héroes para fortificar ciertas ciudades, por ejemplo, Argos y Tirinto. 
3. El síndrome de Patau (niños cíclope), se conoce como la trisomía en el par 13, resulta de presencia de un cromosoma 13 suplementario. Los niños afectados por este síndrome generalmente mueren al poco tiempo de nacer, pues los problemas físicos y cognitivos asociados son severos. (www.nlm.nih.gov/ medlineplus/spanish/ency/artic)

\section{Bibliografía}

Alvarado, O. G. (2006). La incidencia de lo posmoderno en la novela Los Peor, de Fernando Contreras. Káñina. Revista de Artes y Letras. 30 (2), 75-89.

Canguilheim, G. (1962). La monstruosidad y lo monstruoso. Revista Diógenes. 40, 33-47.

Chevalier, J. y Gheerbrant, A. (1988). Diccionario de los símbolos. Barcelona: Editorial Herder.

Contreras-Castro, F. (1995). Los Peor. San José: Ediciones Farben.

Foucault, M. (2001). Los Anormales. Madrid: Ediciones Akal.

García de la Huerta, M. (2001). Sobre catástrofes y monstruos. http//www.oei.es/ [Consulta 12 de febrero de 2014].

González-Hernández, C. (2014). Espacios predominantes en la novela Los Peor de Fernando Contreras Castro. [pdf]. http://www.mep.go.cr/ [Consulta 02 de setiembre de 2014].

Grimal, P. (1979). Diccionario de mitología griega y romana. Barcelona: Paidós.

Harrauer, C. y Hunger, H. (2008). Diccionario de mitología griega y romana. Barcelona: Editorial Herder.

Henríquez, M. (2005). Miradas convergentes sobre la ciudad en Los Peor de Fernando Contreras. Letras. 37 (1), 53-64.

Jiménez, J. (1998). Si algo pudiera llevarme a la muerte eso sería el ruido del mar. Una lectura de Los Peor como estética de los excluidos. Revista Girasol. 2, 41-44.

Rojas, M. y Ovares, F. (1995). 100 Años de Literatura Costarricense. San José: Ediciones Farben. San Isidoro de Sevilla. (2009). Etimologías. Madrid: Biblioteca de Autores Cristianos. 
